\title{
OUTROS TEMAS
}
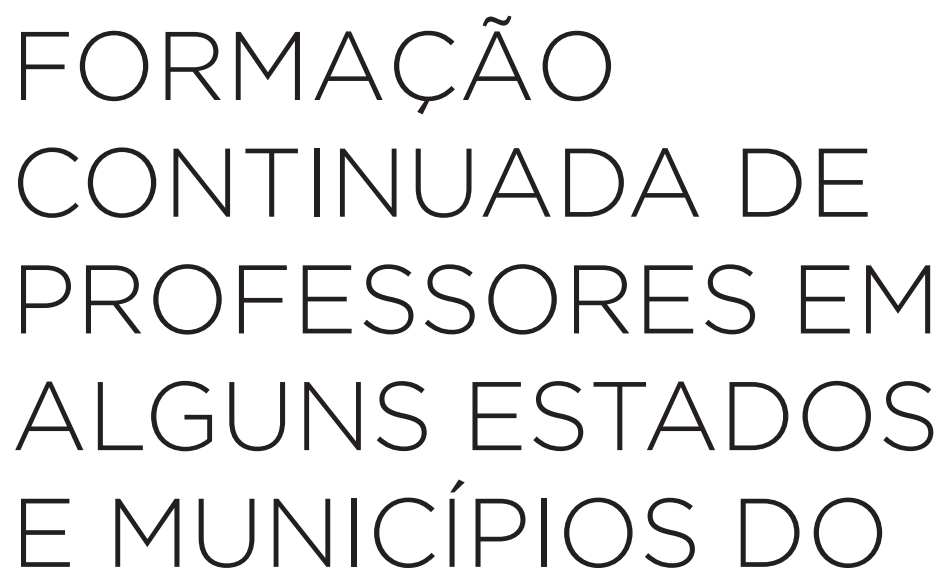

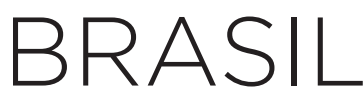

CLAUDIA LEME FERREIRA DAVIS

MARINA MUNIZ ROSSA NUNES

PATRÍCIA C. ALBIERI DE ALMEIDA

ANA PAULA FERREIRA DA SILVA

JULIANA CEDRO DE SOUZA

\section{RESUMO}

O objetivo deste estudo é verificar como se dá a formação continuada de professores em diferentes estados e municípios brasileiros. A coleta de dados incluiu entrevistas com pessoas envolvidas na formação continuada, em dezenove secretarias municipais e estaduais de educação de diferentes regiões do país. Os resultados mostraram a presença de ações orientadas basicamente para as séries iniciais do ensino fundamental, privilegiando as áreas de Língua Portuguesa e Matemática. Duas perspectivas foram encontradas: a individualizada, que busca valorizar o próprio professor, sanando suas dificuldades de formação, e a colaborativa, que se centra em atividades realizadas predominantemente nas escolas, com ênfase no trabalho partilhado. Grande parte dessas secretarias considera que modalidades de formação mais duradouras e sistemáticas são mais produtivas, porque levam os docentes a modificar sua prática pedagógica. Há marcada dificuldade em avaliar e acompanhar a aprendizagem dos docentes ao término de sua participação nas ações de formação continuada. No momento atual, o estudo aponta a importância de as secretarias implementarem, simultaneamente, modalidades voltadas para o professor e para a escola, além de elaborar políticas educacionais internamente mais bem articuladas e mais harmônicas com as demais políticas voltadas para o magistério. Essas parecem ser as melhores alternativas para atualizar os conhecimentos e habilidades necessários para os docentes se aprimorarem em sua profissão. 


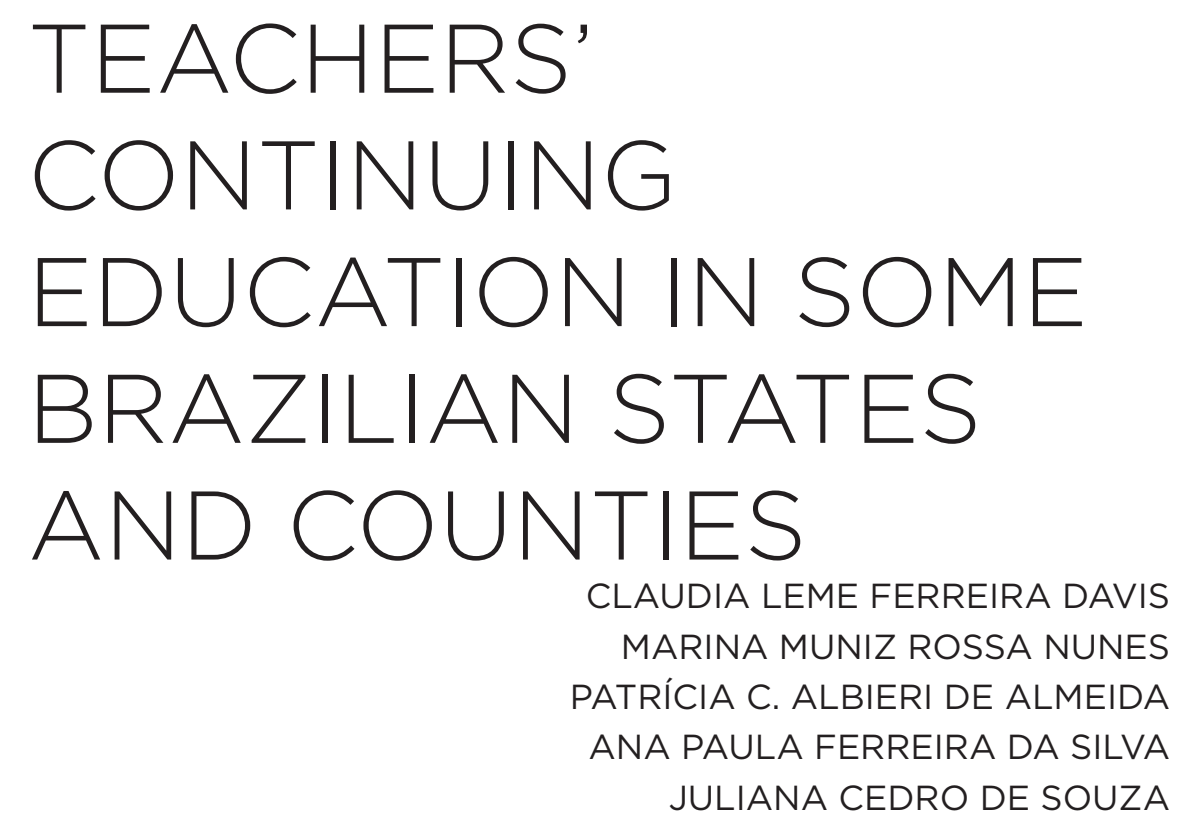

\section{ABSTRACT}

The goal of this study is to identify the main guidelines adopted by some Brazilian states and counties in the offering of Programs of Continuous Education for Teachers (PCET). Data collection involved interviews with personnel from 19 municipal and state Boards of Education, from different regions of the country. The results showed that PCET are offered mainly to teachers who are working in the initial years of the basic schooling, system focusing primarily on the subject of Portuguese and Mathematic. Two main perspectives were adopted: the individual one, which seeks to solve the difficulties and impasses presented in the classroom; and, the collaborative approach, which focuses predominantly on activities that take place in schools, emphasizing cooperative work. Most of these Boards of Education found that more enduring and systematic modalities of PCET are more productive in promoting teachers' learning, eventually leading them to modify their pedagogical practices. There were also many difficulties in evaluating and monitoring the PCET results. The conclusions indicate that, at the moment, the Boards of Education have to make simultaneous use of modalities aimed at the teacher and at the school as well as to strengthen internal educational policies that are better articulated and more harmonious with other teaching policies. These seem to be the best alternatives to upgrade the knowledge and skills of teachers, helping them to develop themselves in their profession. 
ESDE OS ANOS DE 1990, na tentativa de superar os problemas de acesso e assegurar a permanência bem-sucedida dos alunos em escolas públicas com uma nova e melhor qualidade, muitas mudanças têm ocorrido na educação brasileira: reformas curriculares, avaliações censitárias sistemáticas em nível nacional e estadual, implementação do sistema de ciclos etc. Essa tentativa de redemocratizar a educação pública causou, no entanto, desequilíbrios entre a ampliação da oferta de vagas e as possibilidades de as escolas atenderem bem aos seus alunos. Com isso, as condições de trabalho dos docentes acabaram também por piorar muito, tanto que o Ministério da Educação, no final da década de 1990, reconhecia que os professores brasileiros vinham recebendo uma formação insuficiente para promover a aprendizagem de seus alunos (BrasıL, 1999). Essa fragilidade da formação inicial dos docentes é apontada também em estudos acadêmicos, como os de Gatti e Nunes (2009) e Gatti e Barreto (2009).

É nesse contexto de dupla preocupação - com a qualidade da escolarização dos alunos e com o desenvolvimento profissional dos docentes - que a formação continuada de professores - FCP - se torna alvo de interesse, reforçando a necessidade de aprofundar a discussão sobre como, e mediante quais circunstâncias, ela tem contribuído para o desenvolvimento profissional dos docentes e o aprimoramento da educação no País. Esse é, de fato, o objetivo deste estudo: verificar como se dá a FCP em diferentes estados e municípios brasileiros, focando, em especial, as práticas e modalidades mais frequentes e os processos de monitoramento e avaliação empregados. O texto que aqui se apresenta é organizado em quatro 
itens. O primeiro, ao analisar os conceitos básicos do campo, permite ao leitor situar-se em relação à FCP e compreender os modelos encontrados na literatura disponível. O segundo mostra o delineamento metodológico da pesquisa. O terceiro apresenta os resultados obtidos. E o último problematiza os principais achados da pesquisa e os encaminhamentos dela decorrentes.

\section{REVISÃO DA LITERATURA}

Como bem mostram Baldock, Manning e Vickerstaff (2003), o momento atual requer uma grande valorização da educação, pois um país com uma população adequadamente escolarizada apresenta índices de criminalidade mais baixos, melhores indicadores de saúde, menor mortalidade infantil, menores taxas de desemprego e, em especial, menor possibilidade de vir a enfrentar situações de instabilidade econômica. Diante da globalização, portanto, a preocupação com a FCP só fez aumentar, levando à proposição de vários modelos e concepções que, nos estudos analisados, raramente se encontram em estado puro, pois é comum mesclarem características de várias propostas ao mesmo tempo.

A leitura da bibliografia especializada indica que uma ideia recorrente é a de que a FCP se faz necessária em razão das limitações da formação inicial. Nesse sentido, teria como principal função, suprir tais lacunas, uma vez que estas repercutem fortemente no trabalho docente. Esse modelo, conhecido como "modelo do déficit", disputa com outros, que consideram a FCP importante pelo fato de o campo educacional ser muito dinâmico, por exigir permanentemente a produção de novos conhecimentos sobre o processo de ensino-aprendizagem e por cobrar dos professores a expansão e o aprimoramento constante de sua base conceitual e de suas habilidades pedagógicas. Duas perspectivas se destacam: as individualistas, que se centram na figura do professor, e as colaborativas, que defendem a construção de uma cultura de trocas e amparos mútuos entre os docentes, como forma de superar os entraves encontrados em seu trabalho. Ambas serão apresentadas aqui em seus traços mais gerais.

\section{PERSPECTIVAS INDIVIDUALISTAS DE FORMAÇÃO CONTINUADA DE PROFESSORES}

Vários tipos de suposição embasam a vertente individualista, entre elas as seguintes: (i) a maior qualificação dos docentes em termos éticos e políticos permitirá que eles aquilatem melhor sua importância social, conheçam mais seu papel e as expectativas nele colocadas, de modo que possam construir um novo sentido para sua profissão; (ii) a formação inicial dos docentes é aligeirada, sendo central ajudá-los a superar entraves encontrados no exercício profissional relativos à falta de conhecimentos científicos essenciais, de habilidades para o adequado manejo da sala de 
aula e, ainda, de uma visão objetiva sobre questões e temas frequentes no dia a dia escolar, como violência, uso abusivo de drogas, gravidez e/ou paternidade na adolescência etc.; (iii) os ciclos de vida profissional precisam ser considerados, tendo em vista que a experiência docente e suas perspectivas mudam conforme os interesses e necessidades da faixa etária.

\section{O desenvolvimento da ética e do conhecimento político}

Alguns estudos consideram que a FCP integra um projeto pessoal, sendo necessário conferir valor e sentido à atividade docente. Hargreaves (1995), por exemplo, acredita que cabe à formação docente esclarecer, para os educadores, o lugar que ocupam as metas e os objetivos do trabalho docente. Para o autor, se o conhecimento teórico e o prático são centrais para a docência, também o é o sentido que se dá a ela. Por isso, é preciso saber as razões pelas quais os professores ensinam, atentando para as dimensões da ética, da política e da motivação, tratadas sempre em conjunto. A dimensão ética implica preocupar-se genuinamente com o bem-estar e com o desenvolvimento dos alunos. A questão política indica que um bom professor também precisa aprender a refletir de maneira crítica sobre si mesmo, sobre sua profissão e sobre seus alunos, se quiser estar mais preparado para lutar, na escola e fora dela, pela construção de um futuro socialmente desejado. Finalmente, a dimensão motivacional implica recuperar a alegria do ensinar e do aprender, a surpresa diante do novo, a satisfação por enfrentar novos desafios e superar conflitos, sentimentos que, excluídos da escola, deixaram em seu lugar apenas angústia e frustração. Nessa ótica, a formação continuada deve permitir que se viva, na profissão, uma experiência prazerosa, valorizada por permitir desvendar novas formas de ser, pensar e sentir, e por levar à construção de projetos coletivos para o mundo em que se vive.

\section{A superação dos déficits da formação inicial}

No modelo individualista, uma abordagem bastante propagada é a de que cabe à FCP superar as mazelas deixadas pela formação inicial. Essa abordagem centra-se, sobretudo, nas características que faltam aos docentes e, por isso, é denominada de “abordagem do déficit”. Esse modelo pressupõe que os professores pouco ou nada têm a dizer sobre como aprimorar sua formação, motivo pelo qual não podem ser consultados sobre essa questão. A FCP é, portanto, definida em outras instâncias e/ou por níveis hierárquicos superiores dos sistemas de ensino, desconsiderando-se as especificidades dos professores e de seus locais de trabalho. São propostas uniformes, no formato “tamanho único" e "unissex”, cuja meta é atingir o conjunto dos professores, independentemente de sua idade, tempo de experiência, disciplina lecionada e interesses. Essa abordagem perdura e é ainda muito popular, porque está embasada no real: sem formação ade- 
quada, o professor não consegue cumprir bem seu papel, que é o de promover a aprendizagem e a permanência bem sucedida na escola de todos os alunos.

\section{O ciclo de vida profissional em foco}

Sem focalizar diretamente as falhas da formação inicial, a perspectiva que considera o ciclo de vida profissional também entende a FCP como um empreendimento de cunho individual, ligado ao percurso profissional do docente, que nem sempre é ascendente. Para Mevarech (1993, 1995), a carreira do magistério é plena de crises marcadas por experiências negativas, desorientação, sentimentos de anomia e baixa autoimagem, que precisam ser acolhidos, entendidos e trabalhados para possibilitar mudanças subjetivas e objetivas. Essa vertente de FCP defende que os estágios que compõem a carreira docente sejam conhecidos para que se identifiquem neles as necessidades e carências dos professores, justamente para auxiliá-los a enfrentar melhor as etapas da vida profissional.

Fessler (1995), Fuller e Brown (1995) e Gregorc (1973) concordam com os achados acima, e mostram que existem momentos críticos na docência, tais como: (i) o estágio de formação inicial, quando estão em construção as ideias básicas sobre o papel da escola, do professor e do processo de ensino-aprendizagem; (ii) o estágio de entrada no campo profissional, momento em que os professores devem fazer frente às demandas do trabalho, ser bem-sucedidos e enfrentar as muitas pressões vindas do sistema de ensino, dos gestores, dos alunos e de suas famílias, e em que acabam tão assoberbados que não conseguem se dedicar a outras atividades que não as de ensino; (iii) o estágio intermediário da carreira, marcado pela busca de coadunar as pressões sofridas às próprias ideias sobre o magistério, momento em que ocorre uma divisão entre os docentes que se sentem confortáveis no ofício e satisfeitos com a profissão e aqueles que se sentem tão insatisfeitos que colocam em dúvida se optaram corretamente pelo magistério; (iv) finalmente, a etapa da maturidade, que se estende até a aposentadoria, quando os professores se sentem seguros na profissão e são capazes de identificar pontos positivos e negativos na docência, independentemente de como a encaram.

\section{ABORDAGENS COLABORATIVAS}

Esse segundo grupo de estudos sobre FCP difere do primeiro por se centrar no desenvolvimento das equipes pedagógicas (direção, coordenação, corpo docente) das escolas, que deve ocorrer, prioritariamente, no interior de cada uma delas, à luz dos problemas enfrentados. Os estudos dessa vertente dividem-se em dois subgrupos: (i) aqueles que entendem ser o coordenador pedagógico - CP - o principal responsável pelas ações de formação continuada na escola; e (ii) os que buscam fortalecer e legitimar 
a escola como lócus de formação contínua e permanente, de modo a criar nela uma comunidade colaborativa de aprendizagem. Mostra-se, a seguir, como se configuram esses dois pontos de vista, que não são, de maneira nenhuma, mutuamente exclusivos.

\section{O coordenador pedagógico e os processos de formação continuada de professores}

Parte importante dos estudos sobre a FCP entende que seu foco deve recair no coletivo de professores de cada estabelecimento de ensino, atribuindo ao CP o papel central de articular as ações formativas de modo a promover o desenvolvimento da equipe pedagógica, e não o do professor individualmente. Para tanto, é necessária uma organização do tempo escolar que garanta a regularidade dos encontros, a contextualização do que será abordado e a participação dos professores, para que as discussões constituam momentos de real aprendizagem para eles. No âmbito nacional (Christov, 2007; Placco, Almeida, 2003, 2006), entende-se que o CP deve, além de coordenar o trabalho pedagógico na escola, intermediar a formação de sua equipe, segundo as necessidades e demandas da realidade escolar em que se situa. Cabe a ele mobilizar os docentes para elaborar/reelaborar o Projeto Político-Pedagógico - PPP - da escola, auxiliando-os a propor e implementar medidas necessárias, na visão do grupo, relacionadas ao currículo, ao processo de ensino-aprendizagem, à avaliação, aos materiais didáticos e pedagógicos e, ainda, às questões de caráter disciplinar e ético e à interação da escola com sua comunidade.

Em outros países, caso da Grã-Bretanha, nem sempre existe alguém que cumpra as funções do CP.Nos países de língua francesa, como a França e o Canadá, as atribuições desse profissional (que recebe outras designações) são muito semelhantes às previstas no Brasil. No Canadá, o “conselheiro" pedagógico atua nas escolas para auxiliar o corpo docente a gerenciar seu tempo e otimizar a organização e o funcionamento dos ciclos de ensino. O sistema educacional francês não prevê um profissional que atue nas escolas, mas estas podem contar com o auxílio de um serviço de consultoria e apoio educativo, cuja meta é orientar os professores e as equipes pedagógicas de escolas onde o serviço de inspeção geral detecta algum problema.

Fica claro que tanto no Brasil como no exterior, quando a figura do CP existe, sua tarefa é assegurar a qualidade do processo educativo oferecido à população, o que é feito, sobretudo, por meio do acompanhamento e da formação continuada dos professores. No entanto, nas escolas brasileiras, essa concepção de formação contínua do docente realizada nas escolas, mediante a coordenação do $\mathrm{CP}$, nem sempre tem sido bem sucedida. Muitas vezes, quando adotada nas políticas públicas, observa-se que partes substanciais da formação são transferidas para as escolas, e que o $\mathrm{CP}$, obrigado a seguir os ditames governamentais, acaba por perder sua in- 
dependência e a ver os docentes como meros executores de ações que lhes são impostas de fora (SÁ ET AL., 2001). Além disso, sabe-se que nem sempre a ação do CP é pautada pelas necessidades e demandas da escola, sabe-se também que existem inúmeras resistências por parte dos próprios docentes em aceitar suas propostas. Nem sempre sua liderança é reconhecida, seja porque lhe falta formação inicial sólida e/ou experiência de ensino, seja porque sua postura é incompatível com o papel que dele se espera em uma escola democrática.

\section{A escola como lócus de formação contínua e permanente}

Muitas FCPs de natureza colaborativa, sem desconsiderar o papel do CP, dão maior atenção à escola, privilegiando interações ocorridas nos próprios locais de trabalho ou nas demais dependências do sistema educacional. Essa corrente, que incide fortemente no plano institucional, considera que os professores questionam de forma permanente sua prática pedagógica, de modo que uma discussão rica sobre a docência deve identificar seus aspectos críticos, bem como incentivar a experimentação didática, o uso de novas estratégias de ensino e a adoção de uma organização mais eficiente para a sala de aula. Em especial, o diálogo entre os docentes deve construir um clima de confiança e entrosamento, que é traço central das “comunidades de aprendizagem” (Fuldan, Germain, 2006). Nelas, é possível observar e falar acerca do que se faz, e com isso o observado e o dito se convertem em feedback para aprimorar o processo de ensino.

Esses resultados são muito promissores: um maior comprometimento dos docentes em inovar e em experimentar; uma coordenação mais eficiente do trabalho intra e interséries, uma sólida articulação dos diferentes níveis de ensino e um maior empenho em suprimir procedimentos de ensino que não contribuem nem para motivar, nem para provocar nos alunos as aprendizagens pretendidas. Para construir comunidades de aprendizagem, os docentes precisam aprender a explicitar e negociar conflitos; evitar acordos rápidos e simplistas; desenvolver sensibilidade política e ética; conhecer o macro contexto em que se atua, com suas iniquidades e disfunções; combater as mazelas da escola, como também as da sociedade em geral. Defende-se que a "aprendizagem contínua" seja uma noção a ser incorporada à cultura escolar, mediante parcerias estabelecidas entre universidades, unidades escolares e sistemas educacionais. Só atuando em conjunto, torna-se possível formar culturas institucionais nas escolas que ofereçam apoio a professores diferentes em diferentes momentos do ciclo profissional.

\section{PROCEDIMENTOS METODOLÓGICOS}

Identificar como se configuram, atualmente, as ações de formação continuada nas redes públicas de ensino, especialmente no que diz respeito às modalidades e práticas empregadas, implicou visitar Secretarias Muni- 
cipais e Estaduais de Educação - SEs. O estudo envolveu 19 SEs (seis estaduais - SEEs - e 13 municipais - SEMs), sendo que seis localizam-se em capitais, sete em municípios de médio porte e as demais em municípios de pequeno porte, distribuídos nas cinco regiões do País (Norte, Nordeste, Centro-Oeste, Sudeste e Sul). Orientaram a seleção inicial das SEs os seguintes critérios: inclusão das instâncias estaduais e municipais, variedade de porte e presença das cinco regiões do País. Algumas SEs contatadas não aceitaram participar da pesquisa ou não viabilizaram sua concretização em tempo hábil para a coleta de dados, o que resultou em alterações na distribuição regional planejada inicialmente. Foi assegurado às SEs participantes sigilo sobre os dados nelas obtidos e, para isso, optou-se por identificá-las por siglas, que informam se são estaduais ou municipais, a região do país em que se encontram e o porte da cidade (capital, média ou pequena). A listagem final das SEs que compõem este estudo:

TABELA 1

IDENTIFICAÇÃO DAS SECRETARIAS DE EDUCAÇÃO POR REGIÃO DO PAÍS

\begin{tabular}{|c|c|c|c|}
\hline \multirow[b]{2}{*}{ Região } & \multirow{2}{*}{$\begin{array}{l}\text { Secretarias Estaduais } \\
\text { de Educação }\end{array}$} & \multicolumn{2}{|c|}{ Secretarias Municipais de Educação } \\
\hline & & Capital de Estado & $\begin{array}{l}\text { Municípios de médio } \\
\text { ou pequeno porte }\end{array}$ \\
\hline \multirow{2}{*}{ Norte } & SEN1 & \multirow[t]{2}{*}{ SMNcap } & 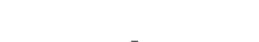 \\
\hline & SEN2 & & \\
\hline \multirow{2}{*}{ Nordeste } & \multirow{2}{*}{ SENE } & SMNEcap1 & SMNEm \\
\hline & & SMNEcap2 & SMNEp \\
\hline Centro-Oeste & SECO & SMCOcap & SMCOp \\
\hline \multirow{2}{*}{ Sudeste } & \multirow{2}{*}{ SESE } & SMSE & SMSEp \\
\hline & & - & SMSEm \\
\hline \multirow{2}{*}{ Sul } & \multirow{2}{*}{ SES } & SMS & SMSp \\
\hline & & - & SMSm \\
\hline
\end{tabular}

Antes do início do trabalho de campo, foi solicitada às SEs, por meio de carta, autorização para a realização da pesquisa, esclarecendo que a adesão implicaria consentimento para entrevistar pessoas que se dedicam à FCP, ocupando cargos de chefia. Em todas as SEs, foram entrevistadas pelo menos três pessoas, dentre elas: o(a) secretário(a) de Educação (ou seu representante); o(a) coordenador(a) de formação continuada (ou o responsável por esse trabalho); um(a) responsável por um projeto, indicado pela SE, como tendo destaque em sua política de FCP.Com base no material obtido (documentos disponibilizados pela SE, registros de campo e transcrição das entrevistas), foram buscados, nos dados de todas as SE, aspectos semelhantes, contrastantes e, inclusive, contraditórios, para que fosse possível selecionar, sistematizar e analisar os principais achados, apreendendo as abordagens e as modalidades de FCP em prática nas SEs estudadas.

\section{BREVE DESCRIÇÃO DAS SECRETARIAS DE EDUCAÇÃO}

Sabia-se, de antemão, que o contexto e as características das SEs investigadas seriam muito variados, mesmo entre aquelas pertencentes a uma mesma categoria: estaduais, municípios-capitais ou municípios de 
médio e pequeno porte. Efetivamente, constatou-se que as jornadas de trabalho oferecidas aos professores são, nas SEs investigadas, bastante diversas e nem sempre incorporam horas para que trabalhem em conjunto. As horas mensais destinadas às atividades de formação continuada podem abranger de $5 \%$ a $35 \%$ da jornada de trabalho do professor. Apenas quatro SEs dispõem de horas destinadas exclusivamente à formação em serviço. Os centros de formação próprios são ainda exclusividade de poucas SEs (cinco), embora tenha sido constante, nas entrevistas, a intenção de conseguir em breve uma sede própria para o trabalho de FCP.

Dentre as SEs que contam com esse recurso, a informação é a de que os centros de formação oferecem, em geral, boa infraestrutura (presença de biblioteca, sala de informática, auditórios pequenos e grandes, salas para formação, pátio e cozinha) e funcionam de segunda-feira a sábado, assessorados por profissionais da área de educação e de administração. É preciso apontar, também, que foram encontrados centros de formação que, a despeito de disporem de boa infraestrutura, ainda não estavam adequadamente organizados como polos efetivos de estudos e de FCP.De fato, eles oferecem, basicamente, salas de aula voltadas para ações pontuais ou para cursos formatados pelas SEs e oferecidos aos docentes interessados. De modo geral, as redes municipais de educação responsabilizam-se pela educação infantil e pelos anos iniciais do ensino fundamental ( $1^{\circ}$ ao $5^{\circ}$ ano). As redes estaduais, por sua vez, ocupam-se, prioritariamente, dos anos finais do ensino fundamental - EF - e do ensino médio - EM. A educação de jovens e adultos - EJA -, uma das modalidades do ensino fundamental, não é ofertada em todas as SEs. De acordo com os entrevistados, a oferta de FCP dirige-se a todas as modalidades de ensino, mas a prioridade são os anos iniciais do ensino fundamental. Constituíram exceções uma SEM da Região Sudeste - SMSEp -, que não dá ênfase a nenhuma modalidade de ensino, e uma da Região Nordeste - SMNEcap1 - que, em 2010, centrava seus esforços na educação infantil.

\section{PRINCIPAIS ACHADOS \\ VISÃO SOBRE AS AÇÕES DE FORMAÇÃO CONTINUADA}

No conjunto dos dados coletados, sobressai uma espécie de "consenso discursivo" ${ }^{1}$ em relação à visão de FCP.Dessa maneira, aspectos mencionados com frequência pelas equipes responsáveis pela FCP nas SEs ouvidas no presente estudo foram os seguintes: a importância conferida aos professores e à sua formação na melhoria da qualidade do ensino; o entendimento de que a formação é o eixo articulador das intervenções na escola; a oferta de FCP pautada pelas avaliações de sistema e a necessidade de promover práticas formativas sistemáticas. Esse modo recorrente de referir-se à FCP parece sugerir que o "consenso discursivo" vigente está estreitamente relacionado à produção de conhecimento na área e às ações políticas adotadas nas últimas décadas em âmbito nacional e internacional (NóvoA, 2007). 1 Nóvoa (2007), em seu texto "O regresso dos professores". 
professores, com as políticas de FCP assumindo relevância estratégica nas ações implementadas nas redes de ensino. Tudo isso confere um papel central aos processos educativos, chamando à responsabilidade professores, gestores, coordenadores pedagógicos e formadores.

As SEs consideram a FCP condição sine qua non para a melhoria da qualidade do ensino. Não constitui fato novo associar a FCP ao aprimoramento das práticas pedagógicas desenvolvidas no cotidiano escolar para promover a aprendizagem dos alunos. Já há muito tempo, as políticas educativas conferem centralidade aos docentes e, por esse motivo, existe a expectativa de que as ações de FCP produzam alterações positivas nos resultados escolares dos alunos, notadamente naqueles obtidos em avaliações de larga escala. Observa-se nos depoimentos a compreensão de que a FCP é um dos eixos estruturantes do trabalho nas SEs, justamente por constituir uma possibilidade de intervir no cotidiano escolar.

As equipes das SEs que obtiveram melhorias no Índice de Desenvolvimento da Educação Básica - Ideb - atribuem esses resultados à FCP, por acreditarem que o nível de formação dos professores interfere na aprendizagem dos alunos. Mesmo compreendendo que a FCP não é a única solução para os problemas de qualidade no ensino, há o entendimento de que ela abre perspectivas de aprimoramento para o processo ensino-aprendizagem. Resulta daí a concessão de maior espaço para a construção de ações coletivas, que almejam aprimorar o trabalho docente. Observou-se também que na maioria das SEs estudadas, a FCP não é entendida como correção da formação inicial, vista quase sempre como precária. Mas se reconhece que há uma série de fatores que atuam como aspectos transformadores do trabalho docente e que é necessário expandir e aprimorar permanentemente os conhecimentos e as habilidades dos professores a fim de atender às novas demandas educacionais. Algumas SEs destacaram que "a formação inicial deixa um monte de lacunas e estas lacunas precisam ser preenchidas" (SEN1, diretor de ensino) - lacunas que desafiam o planejamento e a execução das práticas formativas.

É notória, nos discursos e na agenda das políticas educativas das SEs, a importância dada ao papel renovador das práticas formativas. A maioria das SEs tem concebido a FCP não como um produto a ser assimilado individualmente pelo professor, mediante sua participação em conferências, palestras e cursos. Muitas SEs compreendem que a FCP não pode se restringir ao domínio das disciplinas científicas ou acadêmicas e que as práticas formativas oferecidas aos docentes não podem ser apenas tentativas de suprir eventuais falhas na formação inicial, mas constituem, antes, ações que possibilitam o desenvolvimento profissional e favorecem a gestão escolar.

Pode-se afirmar, assim, à luz dos dados coletados junto às SEs, que as práticas adotadas na FCP têm sido aprimoradas. Há um grande esforço em atender às necessidades dos educadores, como se nota nas tentativas 
de evitar modalidades formativas de caráter isolado, pontual e/ou de curta duração. Entretanto, reconhecer que as concepções, práticas e políticas de FCP vêm evoluindo gradativamente não significa ausência de restrições, limitações e equívocos, nem que os resultados desejados sejam alcançados. Elaborar e implementar ações de FCP são tarefas complexas, que exigem das SEs ações bastante articuladas. Nota-se que algumas SES com melhor nível de organização já constituíram e solidificaram suas políticas de FCP e têm uma visão clara acerca do que é importante oferecer aos professores de suas redes de ensino. Outras ainda não dispõem de uma política de FCP e oferecem aos professores apenas algumas modalidades de cursos, quase sempre promovidos ou apoiados pelo MEC. Mas é unânime o desejo dos professores de contar com uma proposta de FCP para suas escolas, que dê continuidade ao que já foi realizado.

As redes que têm uma política de formação continuada reúnem pelo menos dois aspectos em comum, que explicam seu avanço em relação às demais: (i) a continuidade histórica das ações de FCP; e (ii) a valorização dos profissionais da educação, assegurando-lhes, nos planos de carreira do magistério público, o aperfeiçoamento profissional continuado, com período reservado à formação incluído na carga de trabalho. Das SEs, oito - quatro estaduais (Seco, SEN1, Sese e SES) e quatro municipais (SMScap, SMNcap, SMCOcap e SMSEm) - vêm, ao longo do tempo, construindo e reelaborando suas políticas de FCP.Essas SEs definiram, nos últimos anos, como ação prioritária, o processo permanente de desenvolvimento profissional do professor, o que, na maioria dos casos, implicou a criação de dispositivos referentes à formação e à carreira do magistério público.

As equipes dessas SEs tiveram a possibilidade de permanecer em suas funções durante sucessivas gestões, o que assegurou a continuidade de iniciativas e de ações. Criou-se, com isso, um círculo virtuoso: a continuidade das equipes de gestão facilita a identificação das necessidades da rede e leva, portanto, a um aprimoramento das práticas formativas. Os relatos dessas SEs indicam a construção de um processo no qual a FCP foi evoluindo gradativamente, passando de cursos pontuais a programas e ações de duração mais prolongada, que incidiam nas necessidades identificadas nos professores. O objetivo de fortalecer a escola como espaço formativo e de assegurar a continuidade e a sistematicidade das ações de FCP apareceu como preocupação da maioria das SEs. Parece haver entre elas a compreensão comum de que a "formação continuada não pode ser constituída só por cursos”, devendo "estar incluída na rotina de trabalho da Secretaria e da escola” (SMNcap - Coordenação de Formação Continuada).

\section{PRÁTICAS FORMATIVAS MAIS FREQUENTES}

Buscou-se identificar e analisar as modalidades de formação continuada oferecidas pelas SEs, com ênfase nos conteúdos e estratégias mais utilizados. Não serão abordados aqui todos os programas e ações de FCP 
das diversas SEs, mas apenas aqueles que pareceram exemplificar melhor as ações de responsabilidade governamental. Isto porque, como se sabe, várias ações e programas de FCP são promovidos por Organizações Não Governamentais ou por sistemas de educação gerenciados pelo setor privado, com financiamento de estados ou municípios.

Os resultados da pesquisa apontam que as políticas de FCP de grande parte das SEs investigadas se centram em práticas vistas como "clássicas” (CANDAU, 1997), ou seja, em cursos preparados por especialistas para aprimorar os saberes e as práticas docentes. A literatura a respeito (IMBERnón, 2010; Sztajn, Bonamino, Franto, 2003; Fullan, 1995, 2006; Candau, 1997) questiona esse formato pelo fato de ser, entre outros fatores, basicamente instrumental. Se essa é a perspectiva predominante nas FCP adotadas nas SEs visitadas, avanços podem ser notados e mesmo boas surpresas. Em muitas SEs, notadamente naquelas situadas em municípios de grande porte, coexistem diferentes modalidades de FCP, uma vez que é preciso atingir diferentes objetivos: "a formação continuada, ela pode ser um curso, ela pode ser um workshop, ela pode ser uma oficina mesmo. Ela pode vir em forma de uma formação longa. Você pode variar a estratégia - até é benéfico que se faça isso. A estratégia é usar muitas estratégias diferentes" (SMSEm - coordenadora do ensino fundamental). Esse depoimento ilustra bem a existência de diferentes práticas formativas nas redes de ensino, podendo-se mesmo dizer que o que diferencia a política de FCP das SEs é a ênfase dada às várias modalidades oferecidas e o foco no trabalho individual ou coletivo, como se verá a seguir.

\section{Perspectivas individualizadas}

A perspectiva individualizada busca valorizar o próprio professor, sanando suas dificuldades de formação no que concerne ao domínio de situações próprias da escola atual ou à prática pedagógica. Essa perspectiva também é adotada quando é necessário divulgar mudanças pedagógicas ou implementar novos programas ou políticas das SEs. Predominam, nesses casos, vários formatos: cursos de curta e longa duração, oficinas e ações mais pontuais (como a oferta de palestras, inscrição em congressos, participação em seminários, jornadas etc.), além de ações formativas que consideram o ciclo de vida e o desenvolvimento profissional.

Das práticas formativas individualizadas, a mais encontrada nas SEs é a oferta de cursos de curta duração, a maioria deles presenciais. Há grande variabilidade no formato e na carga horária desses cursos, e eles normalmente tratam de questões relacionadas ao trabalho docente em sala de aula. É possível encontrar ainda, em algumas redes, aqueles que propagam o uso de ferramentas tecnológicas e o trabalho em ambientes virtuais. A explicação para o uso frequente dessa modalidade é genérica: esse tipo de prática parece promover uma maior assiduidade do professor. 
Algumas SEs destacaram a preocupação em manter a continuidade dos cursos, procurando oferecê-los durante todo o ano letivo.

Em diferentes estados e municípios, os cursos de curta duração sofrem ajustes, buscando atender às expectativas dos docentes quanto a uma maior articulação entre teoria e prática e à necessidade oferecer subsídios que auxiliem a implementar mudanças na sala de aula. Algumas SEs (SEN1, SEN2, SES, SMScap, SMNEm, SMSp, SMSm, SMSEm e SMNEcap2) destacaram que o formato de oficinas para os cursos de curta duração funciona bem e é aprovado pelos docentes que delas participam: "Nós verificamos que oficinas que dialogam com as necessidades dos alunos, com as necessidades da sala de aula, têm sido muito mais efetivas. Elas chamam a atenção do professor para problemas que ele enfrenta na sala de aula" (SEN1 - diretor de ensino da SE). Outro aspecto a ser destacado nos depoimentos - e que explica a aprovação dessa modalidade de FCP - é o professor acreditar que conseguirá, por meio das oficinas, não só articular sua prática a aspectos teóricos como também construir materiais e recursos para incorporar ao cotidiano da sala de aula.

A grande maioria das SEs estudadas aproveita os programas do governo federal para ofertar cursos de longa duração aos seus professores. De fato, os relatos indicam que a Rede Nacional de Formação Continuada de Professores tem sido bem utilizada, especialmente pelas SEEs, que formulam demandas e recebem o apoio de universidades cadastradas para ofertar a FCP na área desejada, como é o caso dos programas Gestar e Pró-Letramento. Esses programas são muito elogiados por sua metodologia e por serem bem aceitos pelos professores. O método adotado no Programa Gestar destaca-se, na visão das SEs visitadas, por atender à expectativa dos professores de alcançar novos conhecimentos teóricos sobre o processo de ensino-aprendizagem e, ao mesmo tempo, de desenvolver estratégias pedagógicas que possam ser utilizadas no cotidiano da sala de aula.

As SEs recorrem ainda a ações pontuais de FCP, como palestras, seminários, congressos, jornadas, encontros pedagógicos e outros eventos similares, embora considerem que eles não são ideais. Na visão dessas SEs, ações pontuais tendem a ser insuficientes quando se pretende promover mudanças duradouras nas práticas pedagógicas e aprimorar a qualidade da educação oferecida. Não obstante, essas modalidades de FCP permanecem ocupando o lugar de práticas complementares, interessantes para motivar os docentes, iniciar a reflexão sobre alguns temas e atualizar o conhecimento produzido no campo educacional.

Outra abordagem que se encaixa nas perspectivas individualizadas é aquela que considera o ciclo de vida e o desenvolvimento profissional dos professores. Esse tipo de abordagem só foi encontrado em uma SE da Região Sul - SES -, que criou um programa de desenvolvimento educacional vinculado à progressão funcional do professor na carreira. Trata-se de 
um PFC organizado em rede e articulado ao plano de carreira, destinado a professores com cerca de 20 anos de atuação profissional, que devem “passar nesse programa para ingressar no último nível da carreira” (SES coordenadora estadual do projeto).

Ainda nessa perspectiva individualizada, encontram-se FCP terceirizadas, caso bastante raro nas SEs investigadas: apenas uma delas a adotou (SMSEp). A terceirização consiste em fazer uso de material apostilado, comprado de uma instituição para ser utilizado em toda a rede de ensino, já com um pacote de treinamento embutido para o uso do material e para o esclarecimento das dúvidas dos professores - um atendimento que nem sempre está disponível em horário e local de fácil acesso. Por último, verificou-se que as SEs estudadas vêm abandonando ações pontuais de formação continuada para adotar, em seu lugar, programas de longa duração, que produzem um melhor efeito. A literatura pertinente corrobora esse dado (GARET ET AL., 2001).

\section{Perspectivas colaborativas}

Diferentemente da perspectiva individualizada, encontrou-se, em algumas SEs, o discurso de que a escola deve ser vista e incentivada como um lócus de FCP, pressupondo, como bem expõe Imbernón (2010), que embora a profissão docente tenha uma parte subjetiva, ela implica também uma parte colaborativa. Essa perspectiva centra-se em atividades realizadas nas escolas: grupos de estudos, com acompanhamento sistemático e rigoroso; produção coletiva de materiais para determinadas séries e disciplinas, posteriormente divulgadas nos portais das SEs; envolvimento dos professores nos processos de planejamento, na implementação de ações e em sua avaliação; elaboração de projetos pedagógicos relativos a questões curriculares ou a problemas identificados em sala de aula; formação de redes virtuais de colaboração e apoio profissional entre comunidades escolares e sistemas educacionais, entre outros.

Algumas perspectivas colaborativas apoiam-se fortemente no papel do CP, visto como responsável pela formação continuada dos professores no âmbito escolar, pelo fortalecimento de toda a equipe pedagógica, incluído o diretor, e pela legitimação da escola como espaço de FCP, no qual uns auxiliam os outros. Poucos são os programas e as políticas que têm conseguido, de fato, promover práticas de formação colaborativa. Na SEE da Região Sudeste - Sese -, por exemplo, foi criado um programa de FCP com o objetivo de desencadear o trabalho coletivo na escola. Foram formados grupos de estudo com a incumbência de revisar temas do currículo básico comum - trabalho que resultou em uma nova proposta curricular, paulatinamente aperfeiçoada até o ano de 2009. Existem vários aspectos interessantes nessa modalidade de FCP: o incentivo ao estudo coletivo na escola, com acompanhamento sistemático e criterioso; a possibilidade de valorizar o conhecimento e os estudos; a construção de um projeto coleti- 
vo no próprio local de trabalho, pois é na escola que ocorrem as situações problemáticas que os docentes vivenciam.

Embora apresentem características bem diferentes, duas SEs - uma estadual e outra municipal - desenvolveram uma proposta centrada na autoria do professor que acaba abarcando todos os docentes (SMNEcap2 e SES). A SEM da Região Nordeste incentiva seus professores a divulgar suas práticas pedagógicas, publicando-as na condição de registros de experiências. Essa divulgação, além de incentivar a escrita autoral, acaba se convertendo em livros para serem utilizados pelos alunos. Convencida de que a formação continuada não deve se pautar exclusivamente pela oferta de cursos e preocupada em valorizar o professor, a SEE da Região Sul - SES - elaborou uma proposta em que os professores são estimulados a escrever textos acadêmicos e didáticos. As ações formativas dessas duas SEs constituem importantes estratégias de valorização do professor que, de mero consumidor, passa a ser produtor de conhecimentos. Essa é uma perspectiva colaborativa que valoriza o próprio docente e seus parceiros, favorecendo a comunicação entre eles, bem como a troca de experiências e a possibilidade de compartilhar sentimentos sobre o que se passa na sala de aula e na escola (Imbernón, 2010).

Outro bom exemplo de práticas de FCP colaborativas é o a da secretaria estadual da Região Centro-Oeste - Seco. Dentre as SEs estudadas, esta é a que conta com a política de formação considerada pela literatura a mais inovadora: a escola é vista como lócus por excelência da FCP.A atual política de formação desse estado busca favorecer: a criação de um clima de colaboração entre os professores na escola; a participação dos professores nos processos de planejamento, realização e avaliação dos resultados da escola; a valorização dos saberes e da experiência dos professores. A SE organiza-se para dar apoio à formação desenvolvida nas escolas, oferecendo-lhes condições para criar, de forma institucionalizada, espaços de formação capazes de aprimorar o coletivo de seus profissionais no próprio ambiente de trabalho. Assegura, ainda, aos professores a oportunidade de planejar e/ou repensar sua atuação com base nas demandas de suas respectivas escolas, considerando o currículo e as necessidades de aprendizagem dos seus alunos. Essa SE criou vários centros de FCP com o propósito de auxiliar o trabalho dos profissionais da escola, buscando melhores condições para a realização da docência. Os centros de formação enfrentam o desafio de tomar a prática da escola e suas necessidades como referência para a FCP.É deles a responsabilidade de organizar e promover ações nas próprias escolas, em horários reservados às atividades pedagógicas que estão integradas à jornada de trabalho dos docentes. Esse projeto tem viabilizado uma atuação coletiva, a formação de redes de informações, a troca conhecimentos e alteração de valores por meio de um permanente diálogo. Seu objetivo central é levar os educadores a protagonizar o processo de mudança da própria prática pedagógica. 


\section{FORMAS DE AVALIAÇÃO E ACOMPANHAMENTO}

Os processos de acompanhamento e de avaliação são valorizados pelas equipes envolvidas em FCP, embora todas, sem exceção, revelem dificuldades para executá-los, notadamente no que diz respeito a verificar seu impacto nas salas de aula. Para o acompanhamento das ações de FCP, são buscadas nas escolas informações sobre modificações na prática docente que tenham resultado em uma melhor aprendizagem dos alunos. Em muitos casos, nas diferentes SEs, os responsáveis pela FCP consideram que os CPs são seus principais interlocutores na discussão do desempenho dos professores e alunos.

Várias estratégias são empregadas para verificar a efetividade das ações do CP: preenchimento de relatórios específicos; realização, com frequência regular (semanal ou quinzenal), de reuniões com a equipe de FCP das SEs; análise dos cadernos dos alunos; e até mesmo incentivo ou imposição a observar as salas de aula para poder auxiliar os professores a transporem as atividades realizadas nos cursos de FCP para o cotidiano escolar. Embora as SEs, de modo geral, compreendam a necessidade de observar a ação docente, são poucas as que conseguem implementar essa prática. Muitas afirmam que essa é uma proposta a ser efetivada a longo prazo, cabendo criar antes uma nova cultura docente, capaz de acolher, aceitar e abrir as portas das salas de aula para os CPs. Outros entraves à implementação dessa prática vão do ceticismo quanto à contribuição que esses agentes educacionais podem oferecer aos professores até às dificuldades dos próprios CPs em se apresentar aos docentes como parceiros.

Em algumas das SEs visitadas, é o CP que deve garantir a implementação dos programas de FCP, para que ele esteja em condições tanto de verificar seu impacto como de auxiliar os professores a fazer um uso adequado dos materiais pedagógicos desenvolvidos no órgão central. A maioria das SEs informa que o controle de frequência dos professores nas ações de FCP é rigoroso, pois essa é uma das formas de acompanhar o andamento dos programas, uma vez que eles são oferecidos no horário de trabalho do professor. Além disso, constituem um requisito para que o docente obtenha sua certificação. Em alguns casos, o controle da frequência é a única forma de avaliar os cursos oferecidos.

A avaliação das ações de FCP se dá, em geral, de dois modos: no primeiro, o professor participante avalia a formação que recebeu; no segundo, as SEs buscam verificar o impacto dessa formação na aprendizagem dos alunos, principal meta a ser alcançada. As avaliações do primeiro tipo empregam questionários pouco extensos e, portanto, pouco detalhados; apenas em alguns casos constatou-se o uso de roteiros de avaliação mais aprofundados. Em geral, os participantes não recebem feedback das opiniões que emitiram sobre a FCP.Na segunda perspectiva, a avaliação dos resultados da FCP é indireta, realizada por meio do rendimento dos alunos nas avaliações externas locais e nacionais (como a Prova Brasil) e dos indicadores de qualidade da educação, como o Ideb, caso de sete das 
SEs estudadas. Esses são, de fato, os dados mais utilizados, como já foi dito anteriormente. É importante destacar que quatro SEs visitadas possuem sistemas de avaliação próprios.

Um único exemplo de avaliação direta dos professores foi encontrado nesta pesquisa. Em uma SE da Região Sul, quando os participantes não obtêm, na avaliação, o aproveitamento considerado suficiente pela equipe central, o curso não é validado e, consequentemente, a evolução funcional dos docentes não ocorre. Três aspectos são focados na avaliação feita por essa SE: frequência, participação durante o curso e entrega/apresentação de trabalhos. Para garantir o acompanhamento das atividades, uma estratégia utilizada pela mesma SE é a visita sistemática às escolas feita pelas “equipes de referência”, compostas por um supervisor de ensino e por coordenadores responsáveis pela FCP de diferentes áreas. Cada uma dessas equipes de referência acompanha cinco escolas. Toda segunda-feira, seguindo um cronograma e uma pauta de observação previamente definidos, algumas escolas são visitadas. O trabalho nelas realizado é alvo de análise conjunta das equipes de referência e da gestão escolar. Embora não pretenda avaliar o impacto das ações de formação nas práticas escolares, esse trabalho oferece informações muito detalhadas sobre o que se passa nas escolas, permitindo identificar se o que foi divulgado está sendo cumprido. Além disso, possibilita apreender as novas demandas e orientar o planejamento das futuras ações de FCP.Em especial, essa forma de atuar favorece a construção de uma postura de compromisso e comprometimento com os resultados das escolas, tanto por parte dos formadores da SEM como das equipes gestoras e dos professores.

Outra estratégia utilizada por cinco das SEs investigadas é o acompanhamento supervisionado pelos próprios formadores, que fazem visitas agendadas às escolas. Um bom exemplo é o caso da SEE da Região Centro-Oeste, onde os formadores lotados nos centros de formação são responsáveis pelo acompanhamento de duas, três ou quatro escolas, mantendo com elas contato semanal. As visitas e o acompanhamento de instâncias superiores (como órgãos e outros grupos ligados às SEs) não são incomuns nas escolas, tendo sido encontradas em oito das SEs desse estudo. A SEM da Região Sudeste (SMSEcap), por exemplo, é responsável pela formação dos professores; as visitas mensais (ou quinzenais) feitas às escolas têm dois objetivos: verificar se e como os professores aplicam em suas práticas pedagógicas o que estudaram e aprenderam nos cursos; e identificar as escolas mais frágeis de cada região, pois são elas as que requerem maior auxílio.

\section{CONSIDERAÇÕES FINAIS}

Os resultados mostram uma interface importante nas propostas de FCP, nas equipes que atuam ali, nas escolas e nos docentes. Essas dimensões, se articuladas, permitem a participação de todos no processo de FCP, com resultados interessantes e promissores, do ponto de vista das SEs. A exis- 
tência de ações políticas que reconhecem e dão continuidade a experiências e trabalhos bem-sucedidos de FCP é significativa: nas SEs em que isso ocorre, os programas de FCP tendem a ser aprimorados na medida das necessidades das escolas e dos docentes. A valorização e a manutenção de equipes bem preparadas de FCP são centrais nesse processo, pois a experiência adquirida gera uma crítica mais acurada para diagnosticar o que está ocorrendo nas escolas e entre os professores, criando uma expertise da qual todas as ações formativas se beneficiam. Contar, portanto, com profissionais vinculados às próprias redes de ensino torna as SEs menos vulneráveis a interferências decorrentes das alterações de governo.

Os esforços do MEC no sentido de regulamentar a FCP no país devem ser ressaltados, na medida em que, ao se formular políticas e estratégias, se procura identificar as principais demandas e definir modalidades e condições que possam levar ao sucesso das ações empreendidas, monitorando sua implementação e avaliando seus resultados. Mas tudo isso corre o risco de se tornar inócuo se não houver uma adequada coordenação e articulação com outros programas e políticas voltados para os professores. Certamente, existe a consciência no país de que essa é uma questão urgente, como bem atesta a minuta apresentada à comissão bicameral do Conselho Nacional de Educação, de 2009, com indicações para a construção das diretrizes nacionais para a FCP.

A tendência observada nas secretarias visitadas de valorizar cursos que perduram no tempo e ocorrem de maneira sistemática é bem-vinda, uma vez que ações pontuais deixam efetivamente muito a desejar. Por outro lado, se a maior sistematicidade e duração das atividades imprimem às ações de FCP uma maior efetividade, elas, muitas vezes, não apresentam ainda coerência entre metas, ações e resultados e ainda não se articulam com as demais políticas docentes. Esses dois últimos aspectos acabam repercutindo negativamente na receptividade da oferta de formação continuada e em seu prosseguimento. Para tanto, é preciso que as SEs elaborem políticas formativas que tenham coerência interna (entre objetivos, métodos e resultados buscados) e coerência com as demais políticas voltadas para o desenvolvimento profissional dos professores, articulando-as à da carreira docente e à de salários, entre outras. Um fato salutar é que as SEs estudadas já têm consciência da importância de fortalecer a escola em seu conjunto, e não apenas e exclusivamente o professor. Essa parece ser uma vertente promissora, já em processo de implementação em algumas SEs que vem promovendo a constituição e consolidação da identidade grupal de suas unidades escolares, com normas de interação visando fortalecer o trabalho colaborativo.

Não se encontrou, neste estudo, nenhuma menção à tendência, bem explorada na literatura (HARGREAVES, 1995), de fortalecer a postura ética e o profissionalismo, a responsabilidade pelo coletivo inerente ao magistério e o exercício da cidadania por meio das ações de FCP.Igualmente, ações 
de FCP voltadas para aqueles que se encontram em momentos distintos da carreira do magistério são ainda incipientes. Destaca-se, também, que a avaliação e o acompanhamento das ações de FCP são aspectos a serem mais bem equacionados: sem eles não há como afinar olhares e condutas relativas à aprendizagem dos alunos, à responsabilidade de levar adiante o acordado no projeto político pedagógico, à prática pedagógica e aos problemas enfrentados na escola, participando da tomada de decisão a respeito de como enfrentá-los. Em um país em que a formação inicial dos docentes é reconhecidamente precária, as SEs, para contar com uma política de FCP efetiva, não podem deixar de atender nem às necessidades dos próprios docentes (em termos de conteúdos disciplinares e temas pertinentes ao cotidiano escolar, habilidades pedagógicas, manejo de classe etc.) e nem às da escola (demandas de seu projeto político pedagógico, amparo aos docentes em diferentes momentos de seu desenvolvimento profissional, necessidades de atender às demandas da SE e das famílias dos alunos etc.). Tudo isso exige um equilíbrio que muitas das SEs estudadas ainda precisam conquistar.

Para finalizar, cabe ressaltar que tudo aquilo que é dado por sabido não é dito, e por não ser dito, é esquecido. As análises aqui tecidas servem para relembrar que o aprimoramento da FCP depende de um conjunto articulado de iniciativas, todas elas já conhecidas. Contribuir para o desenvolvimento profissional dos docentes requer, com urgência, que eles sejam considerados como sujeitos ativos, capazes de assumir o papel de especialistas em processos de ensino-aprendizagem e compromissados com a educação das gerações futuras. A função da FCP não é nem a de se centrar apenas no domínio das disciplinas curriculares, nem a de focar as características pessoais dos docentes. Outras metas precisam ser necessariamente consideradas: acentuar as atitudes positivas dos docentes diante de sua profissão, de sua escola, de seus alunos e familiares, ampliando sua consciência ética; revitalizar a luta por melhorias na situação de trabalho, conhecendo melhor os determinantes que atuam em seu contexto de trabalho de modo a alcançar um envolvimento político mais consistente; e, ainda, estabelecer novos padrões relacionais com as equipes gestoras, com seus pares e com a comunidade, para que a escola democrática possa se tornar uma realidade.

Para tanto, cabe novamente afirmar, é preciso investir maciçamente na formação inicial dos professores, de modo que a formação continuada não seja obrigada a atuar retrospectivamente e, portanto, de forma compensatória. É necessária uma formação continuada prospectiva, por meio da qual o professor ganhe mais autonomia, inclusive para opinar em que aspectos e de que formas deve se dar seu aprimoramento profissional. É imprescindível a articulação da formação inicial com a continuada, para que essa última possa se amparar na primeira, colocando os docentes, entre outras metas, em compasso com as mudanças ocorridas no 
campo educacional. É preciso também coordenar a oferta de FCP com as etapas da vida profissional dos docentes, mediante a oferta de programas dirigidos: ao professor ingressante na carreira (oferecendo-lhe subsídios e acompanhamento para apropriar-se do ethos da escola, de sua dinâmica de funcionamento e dos aspectos nos quais precisa ser fortalecido); àqueles que estão mudando de segmento ou de nível de ensino (para que sejam amparados ao longo do processo de adaptação às novas demandas que lhes são colocadas, bem como estimulados a alcançar a desenvoltura necessária para participar ativamente do planejamento escolar, desenvolver seu plano de aula e executá-lo junto aos alunos). Cabe ainda delinear programas de FCP para docentes com mais de quinze anos de docência que, ao voltar à universidade, possam se aprimorar para colaborar na formação de seus pares, recuperando a motivação para ensinar.

Vale relembrar igualmente a importância de desenvolver políticas que formem e fortaleçam, em conjunto, o corpo docente e a equipe gestora (diretores e coordenadores pedagógicos), aproveitando as competências disponíveis e colocando-as a serviço do projeto pedagógico da escola. Gestores e coordenadores pedagógicos precisam também de ações voltadas para suas respectivas funções, notadamente quando atuam nos anos finais do ensino fundamental e no ensino médio e quando trabalham com professores especialistas. Investir na formação desses profissionais implica reconhecer que a escola, sem sua participação ativa, não se transforma em um dos lócus privilegiados da FCP.Da mesma maneira, é necessário ampliar a oferta da FCP para atender aos que atuam em todos os níveis e modalidades de ensino, não se restringindo apenas às áreas de Português e Matemática, privilegiadas em função de serem alvo de avaliações de sistema e comporem o Ideb.

O papel das universidades na FCP continua sendo fundamental. Elas precisam fortalecer propostas que favoreçam sua interação com as comunidades escolares, aspecto nodal para que se inteirem de suas necessidades e demandas. Nessas condições, a universidade contribui mais e melhor para as ações das redes de ensino, auxiliando-as, entre outros aspectos, a entrar em contato com os novos conhecimentos do campo educacional, trazendo o debate acadêmico para o interior das escolas; delineando atividades, cursos e eventos no campus universitário, de modo que os professores das escolas se familiarizem com esse ambiente, e permitindo-lhes, ao mesmo tempo, construir uma visão mais objetiva, porque mais distanciada, de seus locais de trabalho; superando problemas e/ou lidando adequadamente com sua profissão e, desse modo, evitando acatar propostas prontas que não lhes dizem diretamente respeito.

Outro aspecto que não pode ser negligenciado é a importância de incentivar a continuidade de programas bem-sucedidos, para que não sejam 
paralisados por mudanças de gestão ou adoção de políticas partidárias que não necessariamente beneficiem o processo de ensino-aprendizagem. Isso implica investir na socialização de experiências bem-sucedidas de formação continuada em diferentes níveis e modalidades de ensino, de modo que tanto órgãos centrais como formadores, professores, gestores e CPs possam se inspirar nelas para desenvolver e/ou aprimorar suas ações formativas. Cabe também desenvolver ações de FCP que contribuam para aumentar o capital cultural dos docentes, uma vez que, na América Latina, a carreira do magistério tem atraído, particularmente, estudantes que, em razão de restrições financeiras, tiveram pouca possibilidade de investir e/ou participar de atividades como leitura de obras literárias (romances, contos e poemas), frequentar teatros e cinemas, visitar exposições de arte etc.

Ampliar o tempo dedicado às ações de formação continuada, de modo que não se restrinjam às reuniões pedagógicas coletivas realizadas na escola, deve ser algo seriamente considerado. Seria excelente se fossem oferecidas às unidades escolares de cada rede de ensino oportunidades de promover encontros formativos entre elas, com discussões pedagógicas por áreas de conhecimento, e não apenas por ano ou nível de ensino. Além disso, a reflexão vertical intradisciplinar - ou por áreas de conhecimento - poderia prever, sempre que possível, a colaboração dos professores dos anos iniciais do ensino fundamental com aqueles de seus anos finais e destes últimos com aqueles do ensino médio. Talvez se construísse assim um clima de confiança e colaboração, levando as escolas - equipe gestora e corpo docente - a experimentar novas práticas educacionais (submetendo-as ao debate crítico no âmbito das redes de ensino) e empregar as inovações divulgadas nas ações de FCP.

Por último, é igualmente fundamental que se avaliem os resultados dos programas FCP e, portanto, sua qualidade, levando os professores a se apropriarem dos conteúdos e das habilidades oferecidos, diversificando sempre as modalidades de avaliação, liberando as ações formativas de estarem sob a égide exclusiva das avaliações censitárias. Observar a atuação docente em sala de aula, visitar as escolas de forma sistemática para discutir a prática pedagógica e os problemas nelas enfrentados, coadunar esforços entre equipes centrais e equipes escolares, são, entre outras atividades, ricas fontes de informação sobre a qualidade das ações de FCP e sobre a implementação de mudanças nas práticas pedagógicas. Modalidades qualitativas de avaliação das ações de FCP e de acompanhamento de seus resultados podem e devem ser incorporadas pelas unidades escolares, servindo como mais uma ação formativa. Em suma, é central e urgente relembrar a necessidade e a importância de políticas educacionais que permitam a coexistência de programas de desenvolvimento individual e coletivo, capazes de oferecer aos docentes das redes públicas de ensino aprimoramento em sua profissão. 


\section{REFERÊNCIAS BIBLIOGRÁFICAS}

BRASIL. Ministério da Educação. Fundamentos para formação do professor da educação básica. Brasília, 1999. Disponível em:<http://portal.mec.gov.br/setec/arquivos/pdf/esbo\%E2\%80\%A1o4.pdf.>. Acesso em: 17 set. 2010.

BRASIL. Presidência da República. Subchefia para Assuntos Jurídicos da Casa Civil. Decreto $n$. 6.755, 2009. Institui a Política Nacional de Formação de Profissionais do Magistério da Educação Básica, disciplina a atuação da Coordenação de Aperfeiçoamento de Pessoal de Nível Superior no fomento a programas de formação inicial e continuada, e dá outras providências. Disponível em: <http://www.planalto.gov.br/ccivil_03/_Ato2007-2010/2009/Decreto/D6755.htm>. Acesso em: 23 nov. 2010.

BALDOCK, J.; MANNING, N.; VICKERSTAFF, S. Social policy. 2. ed. Oxford: Oxford University, 2003.

CANDAU, V. M. Formação continuada de professores: tendências atuais. In: CANDAU, V. M. (Org.). Magistério: construção cotidiana. Petrópolis: Vozes, 1997. p.51-68.

CHRISTOV, L. H. da S. Educação continuada: função essencial do coordenador pedagógico. In: GUIMARÃES, A. A. (Org.). o Coordenador pedagógico e a educação continuada. 5. ed. São Paulo: Loyola, 2007. p.9-12.

FESSLER, R. Dynamics of teacher career stages. In: GUSKEY, T. R.; HUBERMAN, M. (Ed.). Professional development in education: new paradigms and practices. New York: Teachers College, 1995.

FULLAN, M. Change forces with a vengeance. London: Falmer, 1993.

. The Limits and the potential of professional development. In: GUSKEY, T. R.; HUBERMAN, M. (Ed.). Professional development in education. New York: Teachers College. 1995. p. 253-267.

. Turnaround leadership.San Francisco: Jossey-Bass, 2006.

FULLAN, M.; GERMAIN, C. Learning places. Thousand Oaks: Corwin, 2006.

FULLER, F.; BROWN, O. Becoming a teacher. In: RYAN, K. (Ed.). Teacher education: 74th yearbook of the National Society for the Study of Education. Chicago: University of Chicago, 1995. Part. 2, p.25-52.

GARET, M. S. et al. What makes professional development effective? Results from a national sample of teachers. American Educational Research Journal, v.38, n.4, p.915-945, 2001.

GATTI, B. A.; BARRETTO, E. S. S. Professores: aspectos de sua profissionalização, formação e valorização social. Brasília: Unesco, 2009. (Relatório de pesquisa)

GATTI, B. A.; NUNES, M. M. R. (Org.). Formação de professores para o ensino fundamental: estudo de currículos das licenciaturas em Pedagogia, Língua Portuguesa, Matemática e Ciências Biológicas, 2009. (Textos FCC, n.29)

GREGORC, A. F. Developing plans for professional growth. NASSP Bulletin, v.57, p.1-8, 1973.

HARGREAVES, A. Introduction. In: CLARK, C. M. (Ed.). Thoughtful teaching. Wellington: Cassel, 1995.

IMBERNÓN, F. Formação continuada de professores. Porto Alegre: Artmed, 2010.

MEVARECH, Z. R. Teachers' paths on the way to and from the professional development forum. In: GUSKEY, T. R; HUBERMAN, M (Eds.). Professional development in education: new paradigms and practices. New York: Teachers' College, 1995. p.151-171.

. Who benefits from computer assisted cooperative learning? Journal of Educational Computing Research, v.9, p.451-464, 1993. 
NÓVOA, A. O regresso dos professores. In: CONFERÊNCIA: Desenvolvimento profissional de professores para a qualidade e para a equidade da aprendizagem ao longo da vida. Lisboa: Presidência Portuguesa do Conselho da União Europeia, 27-28 set. 2007.

PLACCO, V. M. de S.; ALMEIDA, L. R. O Coordenador pedagógico e o cotidiano da escola. São Paulo: Loyola, 2003

O Coordenador pedagógico e questões da contemporaneidade. São Paulo: Loyola,

2006.

SÁ, H. A. et al. Coordenação pedagógica e o processo de ensino aprendizagem: as evidências de um exercício acadêmico. 2001. Disponível em: <http//www.ichs.ufop.br/conifes/anais/EDU/edu1601.

htm>. Acesso em: 20 set. 2010.

SZTAJN, P.; BONAMINO, A.; FRANCO, C. Formação docente nos surveys de avaliação educacional. Cadernos de Pesquisa, São Paulo, n.118, p.11-39, mar. 2003.

\section{CLAUDIA LEME FERREIRA DAVIS}

Pesquisadora da Fundação Carlos Chagas e professora da Pontifícia Universidade Católica de São Paulo cdavis@fcc.org.br

\section{MARINA MUNIZ ROSSA NUNES}

Pesquisadora da Fundação Carlos Chagas e professora do Colégio Santa Cruz mnunues@fcc.org.br

\section{PATRÍCIA C. ALBIERI DE ALMEIDA}

Pesquisadora da Fundação Carlos Chagas e professora da Universidade Presbiteriana Mackenzie palmeida@fcc@fcc.org.br

\section{ANA PAULA FERREIRA DA SILVA}

Assistente de Pesquisa Bolsista da Fundação Carlos Chagas e professora da Universidade Presbiteriana Mackenzie

anafsil@yahoo.com

\section{JULIANA CEDRO DE SOUZA}

Assistente de Pesquisa Bolsista da Fundação Carlos Chagas e professora da Universidade Nove de Julho

julianacedro@yahoo.com.br 